\title{
FORMAÇÃO CONTINUADA DE PROFESSORES \\ ALFABETIZADORES: \\ AS (RE)SIGNIFICAÇÕES DOCENTES COM BASE NAS AÇÕES DO PNAIC EM SANTA CATARINA
}

\author{
FORMACIÓN CONTINUA DE PROFESORES ALFABETIZADORES: LAS \\ (RE)SIGNIFICACIONES DOCENTES CON BASE EN LAS ACCIONES DEL \\ PNAIC EN SANTA CATARINA
}
CONTINUING EDUCATION OF LITERACY TEACHERS: THE TEACHER RESIGNATIONS BASED ON THE ACTIONS OF THE PNAIC IN SANTA CATARINA

Maira Gledi Freitas Kelling MACHADO ${ }^{1}$ Marizete Bortolanza SPESSATTO

\begin{abstract}
RESUMO: O presente artigo visa contribuir com as reflexões acerca do papel da formação continuada dos professores no processo de ensino aprendizagem. $\mathrm{O}$ foco das reflexões está centrado na análise da ação de alfabetizadores em formação no Pacto Nacional pela Alfabetização na Idade Certa (PNAIC) e foi produzido a partir da análise dos relatórios de visitas técnicas realizadas em diversos municípios catarinenses envolvidos no processo formativo em questão. A formação do PNAIC no período de 2013 a 2015, no estado de Santa Catarina, proporcionou um curso presencial para os professores alfabetizadores atuantes nas classes de alfabetização do Ensino Fundamental de cerca de 200 horas anuais. Segundo extratos dos relatórios das visitas técnicas da equipe de formadores do programa, realizadas nas turmas de alfabetização, após o processo de formação dos anos de 2013 e 2014, podemos afirmar que o processo constituiu-se como um suporte significativo para auxiliar o trabalho pedagógico dos professores alfabetizadores, permitindo-lhes ampliar conceitos e qualificar a prática pedagógica, mesmo em um cenário de resistências e diante das dificuldades de infraestrutura apresentadas por escolas da rede pública participantes do programa.
\end{abstract}

PALAVRAS-CHAVE: PNAIC. Formação de professores. Alfabetização. Visitas técnicas.

RESUMEN: El presente artículo visa contribuir con las reflexiones acerca del papel de la formación continua de los profesores en el proceso de enseñanza-aprendizaje. El eje de las reflexiones está centrado en el análisis de la acción de alfabetizadores en formación en el "Pacto Nacional por la Alfabetización en la Edad Cierta" (PNAIC) y fue producido a partir del análisis de los informes de visitas técnicas realizadas en diversos municipios del Estado de Santa Catarina (Brasil) que participaron en el proceso formativo en cuestión. La formación del PNAIC en el período de 2013 a 2015, en el estado de Santa Catarina, ha proporcionado un curso presencial para los profesores alfabetizadores actuantes en las clases de alfabetización de la Enseñanza

\footnotetext{
1 Mestre em Educação - UDESC. Centro de Educação a Distância, Florianópolis, Brasil. E-mail: mairakelling@gmail.com.

2 Doutora em Educação. Departamento de Formação - Instituto Federal de Educação, Ciência e Tecnologia de Santa Catarina, IFSCP. Centro de Referência em Formação e EaD, Florianópolis, Brasil. E-mail: marizete.spessatto@ifsc.edu.br.
} 
Fundamental de cerca de 200 horas anuales. Según información de los informes de las visitas técnicas del equipo de formadores del programa, realizadas en los grupos de alfabetización, tras el proceso de formación de los años de 2013 y 2014, podemos afirmar que el proceso se constituye como un soporte significativo para auxiliar el trabajo pedagógico de los profesores alfabetizadores, permitiéndoles ampliar conceptos y cualificar la práctica pedagógica, incluso en un escenario de resistencias y ante las dificultades de infraestructura presentadas por escuelas públicas participantes del programa.

PALABRAS CLAVE: PNAIC. Formación de professores. Alfabetización. Visitas técnicas.

ABSTRACT: This article aims to contribute to the reflections on the role of continuing education of teachers in the transformation of historically ingrained practices in teaching and learning process. The focus of the reflections is centered on the analysis of literacy action in training the National Pact for Literacy in the Age One (PNAIC) and was produced from the analysis of the technical visit reports conducted in several municipalities of Santa Catarina involved in the training process. The formation of PNAIC from 2013 to 2015 in the state of Santa Catarina, provided a classroom course for active literacy teachers in elementary school literacy classes for about 200 hours per year. According to extracts of the visit reports made in literacy classes, after the process of formation of the years 2013 and 2014, we can say that the training process was established as a significant support to assist the educational work of the literacy teachers participating in the program, allowing Them to expand their concepts and qualify the pedagogical practice, even in a scenario of resistance and on the infrastructure gaps presented by public schools participating in the program.

KEYWORDS: PNAIC. Teacher training, literacy. Technical visits.

\section{Introdução}

O presente artigo discorre sobre uma experiência de formação continuada de professores, o Pacto Nacional pela Alfabetização na Idade Certa - PNAIC (BRASIL, 2012a). A partir da análise desse processo, visamos refletir sobre o papel das formações na qualificação do trabalho docente, sobretudo via troca de experiências entre os pares que essas experiências permitem. Em Santa Catarina, cenário da presente análise, as ações do PNAIC iniciaram em 2013, com adesão de 293, dos 295 municípios catarinenses, com mais de oito mil alfabetizadores, 537 orientadores de estudos e 18 formadores envolvidos no processo ${ }^{3}$. As ações foram estruturadas considerando: 1)

${ }^{3}$ Embora o material tenha sido produzido e distribuído, as ações do PNAIC não haviam sido retomadas em 2016, até o momento de fechamento deste artigo. Quanto à sua organização, as formações foram realizadas da seguinte forma: os professores formadores coordenavam os trabalhos com os orientadores de estudos, com uma carga horária de 200 horas de formação ao longo de cada ano. Após esses encontros 
formação dos orientadores de estudos, coordenada por professores formadores e supervisores vinculados à Universidade Federal de Santa Catarina; 2) em cada encontro de formação, tanto os orientadores de estudos quanto os professores alfabetizadores organizaram diários de bordo, sintetizando as leituras dos Cadernos de Formação e de textos complementares, os debates e os avanços alcançados em cada período de formação; 3) os planejamentos de atividades a serem desenvolvidas em sala de aula foram feitos em conjunto entre os professores; e 4) depois dos encontros presenciais com os orientadores, os alfabetizadores retornaram às salas de aula para vivenciar as atividades planejadas e produzir relatórios sobre elas.

Quanto à metodologia, o estudo que deu origem a este artigo caracteriza-se como uma pesquisa qualitativa, com coleta de dados via Análise de Conteúdo (MINAYO, 2007). Essas escolhas permitiram a exploração do material, com a definição de categorias (expressões ou palavras significativas) presentes nos relatórios de visitas técnicas e que expressam os pontos mais marcantes do processo em análise.

Além de apresentarmos um breve relato do processo de formação no estado, os dados aqui em análise fazem parte dos registros efetuados quando das visitas técnicas às escolas pelos formadores para acompanhar as ações dos alfabetizadores, que deveriam estar centradas nos estudos efetuados durante a formação nos anos de 2013, cuja ênfase da formação era para Linguagem, e 2014, com o foco para a Matemática. As visitas técnicas tiveram como propósito verificar em que essa formação interveio nas metodologias desenvolvidas pelos professores em suas turmas de alfabetização. Em consonância com o previsto no Plano de Trabalho Anual do Pacto, foram realizadas visitas breves às escolas, sem aviso prévio.

Os Relatórios das Visitas Técnicas propunham observar, entre outros pontos: (1) Quanto aos materiais: a) As obras complementares e os jogos enviados pelo MEC estão nas salas de aula? b) Como os materiais estão sendo usados pelos professores alfabetizadores? (2) Quanto à formação: a) Quais os impactos da formação no trabalho de docência? Houve mudanças nos planejamentos e práticas em sala de aula? É nesse ponto, voltado à formação, que o presente artigo centrará sua análise.

Assim, tomando como material de análise as impressões contidas em seis relatórios, produzidos pelas autoras, integrantes da equipe de formadoras do Pacto em Santa Catarina, imediatamente após as idas às escolas, tem-se a possibilidade de colocar 
em confronto aquilo que foi estudado/debatido nos encontros de formação e a efetivação desses conhecimentos no processo em sala de aula. Isso porque, mesmo considerando que “[...] um programa de educação continuada altera significativamente a prática docente e a vida do professor" (JARDILINO; NUNES; ARAÚJO, 2012, p.5139), essa efetividade só é possível com a efetiva adesão dos educadores ao processo de formação. Não basta participar de palestras, cursos ou capacitações, é preciso refletir e transformar a prática pelo engajamento às propostas de formação (MACHADO; SPESSATTO, 2016). Prada (2001, p.101) reforça que as formações continuadas são essenciais para a qualidade da educação, porém, “[...] nas experiências que têm dado certo, registram-se outras razões como fatores do seu sucesso, esquecendo-se que são os professores, com suas mudanças de postura, que conseguem transformar a rotina escolar e o quotidiano da sala de aula".

\section{O PNAIC em Santa Catarina: histórico das formações}

As ações do Pacto Nacional da Alfabetização na Idade Certa (PNAIC) em Santa Catarina começaram em fevereiro de 2013. O início do processo foi marcado por dificuldades. Professores alfabetizadores foram convocados pelos municípios para a participação em um programa de longa duração, se comparado aos moldes das formações curtas, via de regra ofertadas nas escolas, o que gerou certo desconforto. Ainda, o controle avaliativo, organizado a partir de um Sistema Integrado de Monitoramento, Execução e Controle (SIMEC), gerou muitas dúvidas. Todos os integrantes do Pacto (professor alfabetizador, orientador de estudo, formador, supervisor, coordenador local, coordenador geral e coordenadores adjuntos) precisaram compreender e atuar no processo avaliativo de todos os perfis contidos nesse sistema e essas avaliações também implicavam no recebimento das bolsas atreladas ao programa. O atraso no repasse dessas bolsas e na entrega dos cadernos de formação, no início dos anos de 2013 e 2014, forma outros entraves enfrentados pelos participantes do programa (AGUIAR, 2016).

Por outro lado, a formação do PNAIC possibilitava amenizar os distanciamentos tão presentes no cotidiano escolar, tais como teoria e prática, professor e aluno, reflexão e ação, dicotomias fortemente marcadas no trabalho docente. As ações dessa formação continuada destinada aos professores alfabetizadores organizaram-se em quatro eixos de 
atuação: capacitação de professores alfabetizadores; distribuição de materiais didáticos e pedagógicos; avaliações; gestão e mobilização. Portanto, o grande destaque da formação foi focado na prática do professor, de modo que as singularidades do trabalho pedagógico tornaram-se objetos de reflexão: “[...] refletir, estruturar e melhorar a ação docente é, portanto, o principal objetivo da formação”. (BRASIL, 2012a, p.28).

Partimos, assim, do pressuposto de que a formação docente só faz sentido se articulada ao cotidiano da prática pedagógica e só pode resultar numa prática de qualidade se o professor tiver condições de refletir sobre a sua ação. Schön (1992) apresenta como proposta para implementação dessa estratégia três conceitos que contribuem para refletir, pensar sobre o professor e sua prática, quais sejam o “conhecimento-na-ação", a "reflexão na ação" e a "reflexão sobre a ação". Ainda que todos os três momentos sejam importantes, consideramos que no trabalho realizado no PNAIC destaca-se a reflexão sobre a ação pois, além de todo material disponível para a formação continuada dos alfabetizadores, cadernos de formação, jogos e literatura infantil, articularam-se estudos acrescidos de autores renomados na área da linguagem, a fim de aprofundar conhecimentos que subsidiam a reflexão sobre a prática. Como exemplo, podemos citar Bakhtin (1992) para aprofundar conhecimentos sobre gêneros do discurso, Brito (2012) para embasar estudos relacionados à leitura e Geraldi (2003) e Smolka (1996) para fundamentar a análise das práticas de produção textual. Dessa forma, ao socializar as experiências desenvolvidas em sala de aula, em todos os encontros de formação, os professores não apenas partilhavam seus conhecimentos e estratégias, mas, junto a seus pares, tiveram a possibilidade de refletir sobre sua prática para, posteriormente, conforme indica Silva (2009), (re)planejar e alterar os pontos necessários.

Ao tomar como elementos de análise os relatórios bimestrais ${ }^{4}$ produzidos pelos orientadores de estudos do Pacto, ao longo de 2013, primeiro ano das formações, Machado e Spessatto (2016, p.74) indicam que, entre as questões que mais impactaram no cotidiano das escolas, no início do processo, estava a fragilidade de compreensão de alguns conceitos-chave da proposta. A formação do PNAIC foi organizada para

\footnotetext{
4 Tanto orientadores de estudos quanto professores alfabetizadores registraram, ao longo das formações de 2013 e 2014 - anos que tomamos por base nesta análise, as atividades desenvolvidas em relatórios. Os orientadores de estudos produziam relatórios mensais com as sínteses das atividades e relatórios completos, entregues bimestralmente, contendo as ações desenvolvidas, reflexões sobre elas e anexos com atividades e fotografias.
} 
envolver professores atuantes no ciclo da alfabetização, tendo como conceito-chave a alfabetização na perspectiva do letramento ${ }^{5}$.

Já no primeiro Caderno de Formação (BRASIL, 2012b) estudado pelos professores, a discussão incluía a distinção entre os termos alfabetização e letramento. Usando Magda Soares como uma das principais referências, o texto chama a atenção para o fato de que:

[...] os problemas que vivenciamos hoje relativos a essa fase da escolarização podem estar relacionados, entre outras coisas, a uma perda de especificidade do processo de alfabetização vivenciado nas duas últimas décadas, relacionada a um processo por ela [a autora] chamado de "desinvenção da alfabetização". (BRASIL, 2012b, p.19).

A impossibilidade de estabelecer um tempo fixo para o processo de alfabetização e letramento da criança está no centro de propostas de mudanças na organização curricular da Educação Básica. A demanda de "[...] espaços e tempos diversos de aprendizagem” (BRASIL, 2013, p.121) é uma das justificativas da alteração dos tempos do Ensino Fundamental, passando este a nove anos, com entrada da criança no primeiro deles aos seis anos de idade. As Diretrizes Curriculares Nacionais da Educação Básica (BRASIL, 2013) sinalizam a necessidade de articulação entre os três primeiros anos da Educação Básica para que esse processo seja contínuo e com avanços progressivos nos conhecimentos linguísticos assegurados às crianças.

Porém, ainda assim observa-se a ausência de diretrizes pedagógicas consistentes para orientar os professores e a ênfase na sistematização do processo de escrita no primeiro ano escolar em detrimento de uma abordagem mais lúdica (BRUNETTI, 2007 apud GUARNIERI; VIEIRA, 2009). Os estudos relacionados às práticas de alfabetização, apontam que Guarnieri e Vieira (2009), têm trazido resultados recorrentes sobre as dificuldades dos professores no desenvolvimento do trabalho de alfabetizar.

5 “O foco na alfabetização enfatiza a apropriação do sistema de escrita alfabético-ortográfico, bem como o desenvolvimento de capacidades motoras e cognitivas pertinentes a esse processo. O foco no letramento, como dimensão complementar e indissociável da alfabetização, privilegia aspectos relativos à inserção e participação do indivíduo na cultura escrita, abrangendo capacidades de uso do sistema de escrita e seus equipamentos e instrumentos na compreensão e na produção de textos, em diversas situações ou práticas sociais”. (BATISTA et al., 2005, p.13). 
Dentre tais resultados, se destacam: a falta clareza sobre o ponto de chegada dos alunos ao final do ano escolar, a perda da noção de terminalidade característica do sistema seriado, sendo que a noção de continuidade do processo que se confunde com a repetição do conteúdo no ano seguinte. (GUARNIERI; VIEIRA, 2009, p.3).

Com foco nas discussões sobre o tema, as formações do PNAIC possibilitaram os debates, moveram a organização coletiva do planejamento pedagógico em momentos de formação e foram tema de produção de relatórios por todos os integrantes do programa (formadores, orientadores de estudos e alfabetizadores.

Se, nos primeiros relatórios produzidos pelos orientadores de estudo, descrevendo o processo de formação com os alfabetizadores, as dificuldades de compreensão dos conceitos-chave da proposta davam a tônica, com o avançar do percurso essas reclamações foram amenizadas. Quando os orientadores de estudos do Pacto foram chamados a responder a um questionário, em 2015, indagados sobre as memórias de formação e sobre a avaliação do que se manteve como efetivo na escola, via ações da formação no Pacto, os destaques foram positivos. "Essa mudança ficou muito evidente ao final do curso: era visível a transformação dos orientadores e, se esses mudaram, certamente fizeram grandes interferências em seus municípios e qualificaram as práticas educativas de seus professores”. (MACHADO; SPESSATTO, 2016, p.74).

$\mathrm{Na}$ seção que segue, buscamos analisar de que modo esse processo se efetivou na prática de sala de aula. Tomando em mãos os relatórios das visitas técnicas realizadas em escolas participantes das formações do PNAIC, buscamos identificar o que foi efetivamente implantado em sala de aula, resultando em mudanças de práticas de alfabetização e letramento.

\section{Um olhar sobre o cotidiano: os relatórios de visitas técnicas do PNAIC em análise}

As formações do PNAIC possibilitaram os debates, moveram a organização coletiva do planejamento pedagógico em momentos de formação e foram tema de produção de relatórios por todos os integrantes do programa (formadores, orientadores de estudos e alfabetizadores. As visitas técnicas, principal foco de análise neste texto, visaram averiguar a aplicabilidade dos debates no contexto da sala de aula.

Alguns pontos permearam o processo formativo e se manifestaram, também, nos registros que constituíram os relatórios. Dessa forma, evidencia-se que o desafio está na 
necessidade de transformação de atitudes pedagógicas, porquanto "[...] planejar requer do professor ser um pesquisador criativo na elaboração da sua aula, estabelecendo prioridades e limites para acolher a criança e sua realidade". (MACHADO; STAUB, 2014, p.374).

O primeiro ponto a ser trazido para análise diz respeito aos acervos encaminhados às escolas para contribuir com o processo de alfabetização. O que a realidade das formações do PNAIC mostrou é que não basta apenas encaminhar material para as escolas. É preciso munir o professor de estratégias para aplicação do que é fornecido para subsidiar a prática docente. Exemplo são os acervos encaminhados nos últimos anos e que, de acordo com relatos coletados durante as formações, só passaram a ser utilizados quando os professores foram chamados à formação, estudando as estratégias metodológicas de inserção das obras literárias e jogos no cotidiano da alfabetização.

Durante o processo formativo, foram discutidas estratégias de uso das obras literárias e jogos, de modo a que esse material passasse da função de coadjuvante, usado apenas em momentos para os quais não haviam atividades planejadas, para o papel principal das atividades com as crianças. Ou seja, livros e jogos precisam ser vistos como materiais que fazem sentido e que enriquecem o processo de leitura e escrita.

No final de 2013, quando das primeiras visitas às escolas para a produção dos relatórios, foi possível perceber que esses materiais passaram a fazer parte do cotidiano da sala de aula: "Na sala, todas as paredes estão forradas com cartazes de Fábulas, projetos didáticos e, ao fundo, pelo canto da leitura com as obras do acervo [encaminhado pelo MEC ainda em 2010]. As crianças têm uma "sacola da leitura", usada para o transporte dos livros da escola para casa. Também está à mostra na sala um livro produzido pelo grupo, com a orientação da professora." (Relatório de visita técnica realizada em escola de Pinheiro Preto). Conversando com as crianças, nas visitas, percebíamos que, efetivamente, esses recursos didáticos passaram a fazer parte da dinâmica da aula (livros de literatura e jogos): “[...] as crianças fizeram questão de mostrar o espaço de leitura e de jogos (jogos também confeccionados a partir de sucata), portanto deu para perceber o quanto exploraram, pois estavam familiarizadas com os recursos" (Relatório de visita técnica realizada em escola de Herval d'Oeste).

Frade (2005) destaca: 
A organização do trabalho de leitura e escrita em classes de crianças de seis anos precisa estar em sintonia com o que é próprio da idade, considerando a experiência prévia das crianças com o mundo da escrita em seus espaços familiares, sociais e escolares e, também, o tempo anterior de frequência à escola. Assim, é preciso criar contextos significativos, trabalhando com temas de interesse e com o amplo mundo da escrita, que desafia as crianças a lidar com a diversidade de textos que elas conhecem e de outros que precisam conhecer, sem perder de vista os conteúdos que se pretende atingir. (FRADE, 2005, p.28).

O modo como a sala de aula é organizada, como os materiais e cartazes ficam dispostos e ao alcance das crianças, enfim, toda essa organização da sala de aula possibilita o trabalho pedagógico na alfabetização de maneira mais adequada, pois garante um suporte eficiente ao ensino da leitura e da escrita. Schwartz (2015) destaca que,

[...] refletir sobre a organização desses ambientes requer considerar que as práticas alfabetizadoras se constituem em articulação com os diversos usos que se fazem da leitura e da produção oral e escrita de textos da escrita e, ao mesmo tempo, exercem a cidadania. (SCHWARTZ, 2015, p.9).

Portanto, a organização do trabalho escolar, preparando a sala de aula como um ambiente alfabetizador, precisa "[...] ser pensada de modo que façam sentido para as crianças, elas necessitam ser pensadas e organizadas em função do que as crianças sabem, desejam e necessitam aprender". (SCHWARTZ, 2015, p.12).

De um modo geral, uma das mudanças mais visíveis das formações foi em relação ao aspecto físico das salas de aula do ciclo de alfabetização. O material disponibilizado como livros e jogos passou a fazer parte do cenário das salas, como se evidencia em mais um dos relatórios analisados:

[...] nas salas de aula está disponível uma variedade de cartazes, como alfabeto, números, calendário, chamadinha. No fundo da sala e ao lado da mesa da professora, as crianças têm livre acesso às caixas com materiais manipuláveis, tais como alfabeto móvel, jogos confeccionados pela professora, tampinhas de garrafas, ente outros. Também estão acessíveis a caixa de jogos e os livros de literatura disponibilizados a partir da formação do PNAIC. (Relatório de visita técnica realizada em escola de São João do Oeste).

No trabalho de Franz, Felipe e Machado (2014), percebe-se como esses "Cantinhos de Leitura" foram organizados de diversas formas pelas professoras, assim como foram incluídos no planejamento escolar. 
[...] despertando interesse pela forma lúdica que foram disponibilizados: desde prateleiras, selecionando algumas obras em destaque na semana; mural com fantoches; tapetes e almofadas; pufes, que estão disponíveis para a hora da leitura. Algumas professoras transformaram caixotes de madeira, como espaço para organizar os livros, sendo pintados pelos próprios alunos. [...] O planejamento para o uso dos livros do "Cantinho da Leitura" se divide entre os momentos específicos para leitura, dentro do projeto de trabalho pedagógico, mas também para quando as crianças terminam suas tarefas antes dos colegas, aproveitando um momento que poderiam ficar ociosos para realizar a leitura deleite, com ou sem a ajuda de alguém que possa fazer a leitura, caso o aluno não seja, ainda, alfabetizado. (FRANZ; FELIPE; MACHADO, 2014, p.3).

Um dos destaques mais relevante diante do uso do acervo de literatura infantil encaminhados às escolas é o fato de os livros estarem ao alcance das crianças, permitindo se "[...] sentirem à vontade para pegar um exemplar, folhear, ler e depois devolver, ou até mesmo levar para casa para concluir a leitura." (FRANZ; FELIPE; MACHADO, 2014, p.10). Por outro lado, é preciso considerar que apenas deixar dispostos os mais variados tipos de materiais, manipuláveis ou não, não garante que de fato a alfabetização aconteça. É necessária atenção dos alfabetizadores aos momentos de planejamento para fazer uso de forma adequada de todos os recursos que têm disponíveis. Goulart (2006) alerta para alguns pontos que devem ser considerados:

A forma como organizamos o trabalho pedagógico está ligada ao sentido que atribuímos à escola e à sua função social; aos modos como entendemos a criança; aos sentidos que damos à infância e à adolescência e aos processos de ensino-aprendizagem. (GOULART, 2006, p.86).

O que fica evidenciado, então, é que não basta apenas dispor os materiais, assim como disponibilizar recursos e preparar a aula. Organizar o trabalho pedagógico requer muito mais atenção por parte do professor, pois a eficiência e desempenho de uma alfabetização estará atrelada ao olhar que este professor tem desta criança, suas considerações diante do que ela sabe e o que ainda precisa aprender.

O segundo ponto a ser discutido, aqui, a partir dos registros de relatórios de visitas técnicas, é que, por mais que exista boa vontade do professor, são necessárias condições de infraestrutura nas escolas para que ações se efetivem. A exigência de condições adequadas para as escolas está descrita no Plano Nacional de Educação, que estabelece como na Meta 7 (BRASIL, 2014) assegurar a todas as escolas públicas de Educação Básica itens de infraestrutura, tais como: água tratada e saneamento básico, 
energia elétrica, acesso à internet com banda larga de alta velocidade, acessibilidade à pessoa com deficiência; bibliotecas; espaços para prática esportiva; acesso a bens culturais e à arte; e equipamentos e laboratórios de ciências.

Embora as informações disponíveis no site do "Todos pela Educação" (TODOS PELA EDUCAÇÃO, [S.d]) registram que as regiões Sul e Sudeste foram as que mais ampliaram o percentual de escolas com infraestrutura adequada, conforme preconiza a meta do Plano Nacional, podemos perceber nos extratos dos relatórios aqui em análise que há muito o que se avançar para melhoria dessa infraestrutura. Com relação às bibliotecas e, consequentemente, aos livros de literatura distribuídos já em 2013, constatou-se: "A biblioteca está impossibilitada de receber alunos devido a uma reforma, por isso muitos livros de literatura infantil, incluindo os recebidos pelo MEC, foram disponibilizados nas salas de aula" (Relatório de visita técnica realizada em escola de Princesa).

Ainda que a escola enfrente problemas estruturais, principalmente quanto às bibliotecas escolares, percebemos que as equipes pedagógicas, junto com seus professores, organizam-se com elementos simples para atuar essas problemáticas, oferecendo às crianças um espaço, ainda que dentro de suas salas de aula, propício ao incentivo à leitura. Algumas salas de aula visitadas possuíam "cantinhos de leitura” com tapete, almofadas e livros dispostos e acessíveis às crianças. Evidenciou-se a criatividade para colocar os livros à disposição das crianças e, assim, garantir o estímulo à leitura. "A escola está situada na zona rural do município, contendo apenas duas salas de aula, cozinha e refeitório. As crianças possuem um amplo espaço para brincar durante educação física e recreio. Contudo, não existe biblioteca escolar, contando com a organização de cantinho de leitura com livros de literatura que são atualizados constantemente pela professora" (Relatório de visita técnica realizada em escola de São João do Oeste).

Mesmo em espaços pequenos, como a sala de aula da professora alfabetizadora de Dionísio Cerqueira, percebemos a mobilização da criatividade para solucionar situações causadas pela falta de estrutura: 
Embora a sala de aula do $1^{\circ}$ ano seja bastante pequena, a professora usa de organização e praticidade [...] organiza os cartazes e produções dos alunos com muita rotatividade, [...] os livros de literatura infantil (poucos - aqui ela dispõe apenas alguns) estão dispostos numa caixa pequena, decorada, porém acessível aos alunos e que ela troca constantemente conforme o interesse do projeto que estão estudando. (Relatório de visita técnica realizada em escola de Dionísio Cerqueira).

Tardif (2002) destaca que o professor não atua sozinho. Ele se encontra em constante interação com outras pessoas e principalmente com os estudantes. Portanto, o autor assegura que:

A atividade docente não é exercida sobre um objeto, sobre um fenômeno a ser conhecido ou uma obra a ser produzida. Ela é realizada concretamente numa rede de interações com outras pessoas, num contexto onde o elemento humano é determinante e dominante e onde estão presentes símbolos, valores, sentimentos, atitudes, que são passiveis de interpretação e decisão, interpretação e decisão que possuem, geralmente, um caráter de urgência. Essas interações são mediadas por diversos canais: discurso, comportamentos, maneiras de ser, etc. Elas exigem, portanto, dos professores, não só um saber sobre o objeto de conhecimento nem um saber sobre uma prática e destinado principalmente a objetivá-la, mas a capacidade de se comportarem como sujeitos, como atores e de serem pessoas em interação com pessoas. (TARDIF, 2002, p.49).

Essa constante busca por adequar as condições encontradas nos espaços escolares com as demandas recebidas no processo de formação aqui em análise e suscetíveis à verificação (escrita de relatórios e visitas técnicas), mobilizaram nos professores esses saberes descritos por Tardif (2002). Porém, mais do que apenas cumprir com um protocolo estabelecido, espera-se que essas ações se efetivem como práticas comuns no cotidiano desses alfabetizadores.

\section{Considerações finais}

Um emaranhado de questões permeia o cotidiano da sala de aula, com seus avanços e percalços, e também constitui o trabalho docente de professores alfabetizadores. Grande parte dessas questões ficaram de fora da presente análise, considerando os objetivos aqui propostos para discussão. Porém, alguns aspectos abordados merecem destaque, quando retomamos os dados de análise para a finalização deste breve diálogo. 
Começamos pelo processo de formação continuada de professores. Gatti (2012) afirma que muitos dos programas de formação continuada lançados nos últimos anos foram motivados por "[...] problemas levantados quanto à formação inicial oferecida nas licenciaturas àqueles que serão futuros professores da educação básica" (GATTI, 2012, p.427). Ainda, é preciso ter em mente a constante necessidade de formação para que novos estudos e reflexões sobre a prática pedagógica cheguem àqueles que, efetivamente, atuam em sala de aula. De todo modo, a resistência a participar de um processo formativo foi sentida no PNAIC. Embora o anúncio da liberação de bolsas tenha servido como um dos motivadores iniciais, as transformações no espaço escolar é que asseguraram o sentimento de pertencimento à proposta.

Se mudam os sentidos da formação, mudam as práticas em sala de aula. O que a análise dos relatórios de visitas técnicas apresentou como mais evidente é que a incorporação de práticas ao cotidiano da alfabetização se dá quando elas são definidamente discutidas e os propósitos tornam-se claros aos professores. Mesmo que possa parecer pequenas, as (res)significações docentes construídas a partir das ações do PNAIC em Santa Catarina são passos dados em direção de um processo de alfabetização construído na perspectiva do letramento. Espera-se que a efetivação de mudanças na organização pedagógica possa abrir portas para que as crianças adentrem o espaço da leitura de modo a, também elas, (res)significarem o cotidiano.

\section{REFERÊNCIAS}

AGUIAR, M. A. L. A supervisão em um dos polos de formação do Pacto Nacional pela Alfabetização na Idade Certa - PNAIC (2013-2014) em Santa Catarina. In: SILVEIRA, E. et al. (Org). Alfabetização na perspectiva do letramento: letras e números nas práticas sociais. Florianópolis: UFSC/CED/NUP, 2016. p.31-43.

BAKHTIN, M. Os gêneros do discurso. In: BAKHTIN, M. Estética da criação verbal. São Paulo: Martins Fontes, 1992. p.261-306.

BATISTA, A. A. G. et al. Avaliação diagnóstica da alfabetização. Belo Horizonte: Ceale/FaE/UFMG, 2005.

BRASIL. Ministério da Educação. Diretrizes Curriculares Nacionais gerais da educação básica. Brasília: MEC/SEB/DICEI, 2013.

BRASIL. Ministério da Educação. Secretaria de Educação Básica. Diretoria de Apoio à Gestão Educacional. Pacto nacional pela alfabetização na idade certa: currículo na alfabetização: concepções e princípios: ano 1: unidade 1. Brasília: MEC/SEB, 2012a. 
BRASIL. Ministério da Educação. Pacto Nacional pela alfabetização na idade certa: formação do professor alfabetizador: Caderno de apresentação. Brasília: MEC/SEB, 2012b.

BRASIL. Ministério da Educação. Plano Nacional de Educação 2014-2024 [recurso eletrônico]: Lei $\mathrm{n}^{\mathrm{o}}$ 13.005, de 25 de junho de 2014, que aprova o Plano Nacional de Educação (PNE) e dá outras providências. Brasília: Câmara dos Deputados, Edições Câmara, 2014. (Série legislação; 125). Disponível em: <http://www.observatoriodopne.org.br/uploads/reference/file/439/documentoreferencia.pdf>. Acesso em: 29 ago. 2016.

BRITTO, L. P. L. Leitura e escrita na educação escolar de crianças pequenas. In: BRITTO, L. P. L. Inquietudes e desacordos: a leitura além do óbvio. Mercado de Letras, 2012. p.99-118.

FRADE, I. C. A. S. Formas de organização do trabalho de alfabetização e letramento. In: BRASIL, Ministério da Educação. Alfabetização e letramento na infância. Brasília: MEC/ SEB, $2005 . \quad$ Disponível em: <http://www.tvbrasil.org.br/fotos/salto/series/150630AlfabetizacaoeLetramento.pdf $>$. Acesso em: 20 ago. 2016.

FRANZ, C.; FELIPE, J.; MACHADO, M. K. PNAIC: o uso da literatura infantil como mediação para a formação do professor alfabetizador. In: ENCONTRO NACIONAL DE DIDÁTICA E PRÁTICA DE ENSINO, Fortaleza, 2014. A didática e a prática de ensino nas relações entre escola, formação de professores e sociedade: caderno de resumos: pôsteres e painéis. Fortaleza: Ed. da UECE, 2014. p.1-528. Disponível em: <http://www.uece.br/endipe2014/ebooks/livro2/PNAIC\%20O\%20USO\%20DA\%20LIT ERATURA\%20INFANTIL\%20COMO\%20MEDIA\%C3\%87\%C3\%830\%20PARA\%2 0A\%20FORMA\%C3\%87\%C3\%83O\%20DO\%20PROFESSOR\%20ALFABETIZADO R.pdf>. Acesso em: 20 ago. 2016.

GATTI, B. Formação de professores e profissionalização: contribuições dos estudos publicados na Rbep entre 1998 e 2011. Revista Brasileira de Estudos Pedagógicos, Brasília, v.93, n.234, p.423-442, mai./ago. 2012. Edição especial.

GERALDI, J. W. Portos de passagem. São Paulo: Martins Fontes, 2003.

GOULART, C. A organização do trabalho pedagógico: alfabetização e letramento com eixos norteadores. In: BRASIL. Ministério da Educação. Ensino Fundamental de nove anos: inclusão para crianças de seis anos de idade. Brasília: MEC, 2006. Disponível em: <http://portal.mec.gov.br/seb/arquivos/pdf/Ensfund/ensifund9anobasefinal.pdf $>$. Acesso em: 20 ago. 2016.

GUARNIERI, M. R.; VIEIRA, L. C. Alfabetização no ensino fundamental de nove anos: desempenho dos alunos e suas implicações para as práticas pedagógicas. Revista Ibero-americana de Estudos em Educação, Araraquara, v.4, n.2, 2009. Disponível em: <http://seer.fclar.unesp.br/iberoamericana/article/view/2779>. Acesso em: 9 ago. 2016. 
JARDILINO, J. R. L.; NUNES, C. M. F.; ARAÚJO, R. M. B. A universidade e a formação de professores: impactos das ações formativas no trabalho docente. In: XVI ENDIPE - Encontro Nacional de Didática e Práticas de Ensino - UNICAMP, Campinas, 2012. Anais... Campinas: UNICAMP, 2012.

MACHADO, M. K.; SPESSATTO, B. M. Ressignificando a docência: as mudanças na prática cotidiana asseguradas pelas formações do PNAIC. In: SILVEIRA, E. et al. (Org). Alfabetização na perspectiva do letramento: letras e números nas práticas sociais. 1.ed. Florianópolis: NUP, 2016. p.67-77. Disponível em: <http://pnaic.ufsc.br/files/2016/06/Alfabetiza\%C3\%A7\%C3\%A3o-na-perspectiva-doletramento-letras-e-n\%C3\%BAmeros-nas-pr\%C3\%A1ticas-sociais.pdf $>$. Acesso em: 20 ago. 2016.

MACHADO, M. K.; STAUB, T. PNAIC: relatos de experiência de uma formação continuada para a garantia de uma alfabetização de sucesso. In: IV COLÓQUIO INTERNACIONAL DE EDUCAÇÃO, DIVERSIDADE E AÇÃO PEDAGÓGICA, Joaçaba, 2014. Anais... Joaçaba: UNOESC, 2014. p.371-380 Disponível em: <http://editora.unoesc.edu.br/index.php/coloquiointernacional/article/view/5147>.

Acesso em: 11 dez. 2016.

MINAYO, M. C. S. O desafio do conhecimento: pesquisa qualitativa em saúde. 10.ed. São Paulo: Hucitec, 2007.

PRADA, L. E. A. Formação continuada de professores: experiências em alguns países. Revista Online da Biblioteca Professor Joel Martins, Campinas, v.2, n.3, p.97-116, jun. 2001.

SCHÖN, D. A. Formar professores como profissionais reflexivos. In: NÓVOA, A. (Org.). Os professores e a sua formação. Lisboa: Instituto de Inovação Educacional, 1992. p.93-114.

SCHWARTZ, M. C. et al. Aprofundando os conhecimentos: a organização do trabalho pedagógico na alfabetização. In: BRASIL. Secretaria de Educação Básica. Diretoria de Apoio à Gestão Educacional. Pacto Nacional pela alfabetização na idade certa: a organização do trabalho escolar e os recursos didáticos na alfabetização - Caderno 04. Brasília: MEC/SEB, 2015. p.9-18.

SILVA, M. Complexidade da formação de profissionais: saberes teóricos e saberes práticos. São Paulo: Cultura Acadêmica, 2009.

SMOLKA, A. L. B. Discutindo pontos de vista. In: SMOLKA, A. L. B. A criança na fase inicial da escrita: a alfabetização como processo discursivo. São Paulo: Cortez, 1996. p.50-60.

TARDIF, M. Saberes docentes e formação profissional. 3.ed. Tradução de F. Pereira. Petrópolis: Vozes, 2002.

TODOS PELA EDUCAÇÃO (Org.). Menos de 5\% das escolas tem estrutura adequada ao PNE. [S.1.]: Todos pela educação, [S.d.]. Disponível em: 
<http://www.todospelaeducacao.org.br/reportagens-tpe/30192/menos-de-5-das-escolastem-infraestrutura-adequada-ao-pne/>. Acesso em: 29 ago. 2016.

\section{Como referenciar este artigo}

MACHADO, Maira Gleidi Freitas Kelling; SPESSATTO, Marizete Bortolanza. Formação continuada de professores alfabetizadores: as (re)significações docentes com base nas ações do PNAIC em Santa Catarina. Revista Ibero-Americana de Estudos em Educação, Araraquara, v.11, n. esp. 4, p. 2483-2498, 2016. Disponível em: <http://dx.doi.org/10.21723/riaee.v11.n.esp4.9205>. E-ISSN: 1982-5587.

Submetido em: setembro/2016

Aprovado em: novembro/2016 